\title{
MicroRNA-205 suppresses the growth of adrenocortical carcinoma SW-13 cells via targeting Bcl-2
}

\author{
YIGAO WU*, WEI WANG ${ }^{*}$, WEILIE HU, WENQING XU, GE XIAO, \\ QIWEI NIE, KEYU OUYANG and SHUAI CHEN
}

Department of Urology, Guangzhou General Hospital of Guangzhou Military Command, Guangzhou, P.R. China

Received April 6, 2015; Accepted July 17, 2015

DOI: 10.3892/or.2015.4295

\begin{abstract}
Compared to adrenocortical adenoma (ACA), adrenocortical carcinoma (ACC) has very poor prognosis and limited treatment options. Also conventional methods to distinguish ACC from ACA can be difficult. At this time, no molecular pathological markers are reliable enough to distinguish either tumor. Recently, increasing data have indicated miRNAs to be crucial regulators in the tumor-related processes. In the present study, we found that miR-205 expression is significantly suppressed in ACC tissues compared with ACAs, and that this induces apoptosis and impairs proliferation of ACC SW-13 cells in vitro as well as inhibits tumor growth in vivo. Using bioinformatic predictions, Bcl-2 was identified to be a target of miR-205 via 3'-untranslated region (3'UTR) interactions, which was confirmed by luciferase assay, qRT-PCR, immunohistochemical assay and western blotting showing that mRNA and protein expression of $\mathrm{Bcl}-2$ were negatively related to miR-205. Further investigation into the mechanism found that activation of Bcl-2 cleaved Bax, releasing caspase- 9 and -3 that are involved in the intrinsic apoptosis pathway, eventually inducing SW-13 cell apoptosis. In conclusion, miR-205 suppresses the growth of ACC SW-13 cells via targeting the anti-apoptotic gene Bcl-2.
\end{abstract}

\section{Introduction}

Adrenocortical carcinoma (ACC) is a rare but aggressive endocrine malignancy with an incidence of $\sim 1-2 /$ million annually and a 5-year survival rate of $16-44 \%$ (1-3). Currently, there is limited information concerning the molecular pathology and pathogenesis of ACC and there is no effective

Correspondence to: Professor Weilie Hu, Department of Urology, Guangzhou General Hospital of Guangzhou Military Command, 111 Liuhua Road, Guangzhou, Guangdong, P.R. China

E-mail: huwl-mr@vip.sina.com

${ }^{*}$ Contributed equally

Key words: miR-205, Bcl-2, adrenocortical carcinoma, SW-13 cells, apoptosis therapy. In addition, distinguishing ACC from adrenocortical adenoma (ACA) using conventional histology and imaging can be difficult. Presently, no molecular pathological markers are able to reliably distinguish between the two cancers. Thus, local invasion or distant metastasis is the only absolute demonstration of malignancy (4). Given the rarity and poor survival rate of ACC and the high prevalence of ACA in the general population (5), as well as the different treatments used (6), the use of biomarkers to confirm the type of adrenocortical tumors (ACT) is required. These markers are also therapeutic targets and prognostic indicators for ACC.

MicroRNAs (miRNAs) are 19-25 nucleotide small, noncoding RNAs involved in $30 \%$ of human gene expression via binding to target mRNAs $(7,8)$. Previous data showed that small RNAs are misregulated in human tumors and can serve as either oncogenes or tumor suppressor genes (9-11). Functional studies suggest that aberrant miRNA expression is a key to cancer development, including cell proliferation, apoptosis and differentiation (12). Due to specific expression patterns and tremendous regulatory capacity, miRNAs are being assessed as potential biomarkers to help diagnose and treat different types of cancers, including ACC. However, limited miRNA expression analyses have been performed on ACC.

We noted downregulation of miR-205 expression in ACC samples compared to ACAs. Overexpression of miR-205 not only induced apoptosis and impaired proliferation of ACC SW-13 cell in vitro, but also inhibited tumor growth in vivo. Furthermore, miR-205 inhibited Bcl-2 mRNA and protein expression via 3'-untranslated region (3'UTR) interaction; this activated the intrinsic apoptosis pathway in SW-13 cells. Therefore, Bcl-2 is a critical anti-apoptotic gene involved in the intrinsic apoptotic pathway (13), and it is a target via which miR-205 inhibits SW-13 cell proliferation.

\section{Materials and methods}

Cell line, tissues and mice. A SW-13 cell line was purchased from the Cell Repository of the Chinese Academy of Science and originated from the American Type Culture Collection (ATCC; Manassas, VA, USA). Cells were cultured in Leibovitz-15 (L-15) media at $37^{\circ} \mathrm{C}$ without $\mathrm{CO}_{2}$. Then, 32 cases of ACC and ACA tissue samples were obtained from the Guangzhou General Hospital of People's Liberation Army. Clinical characteristics of the study cohort are summarized 
Table I. Clinical characteristics of the study cohort.

\begin{tabular}{lrr}
\hline Characteristics & ACC & ACA \\
\hline No. of patients & 11 & 21 \\
Age (average \pm SD) & $53 \pm 12$ & $48 \pm 16$ \\
Gender (female/male) & $8 / 3$ & $14 / 7$ \\
Syndrome & & \\
Cushing's & 7 & 7 \\
Subclinical Cushing's & 0 & 1 \\
Conn's & 0 & 3 \\
Non-functioning & 4 & 10 \\
\hline
\end{tabular}

ACC, adrenocortical carcinoma; ACA, adrenocortical adenoma; SD, standard deviation.

in Table I. Tumors were classified as ACC when the Weiss criteria were $\geq 3$. Tumors were classified as benign when the Weiss criteria were $<3$ (14). Female nude mice 4 weeks of age were provided by the Animal Center of Southern Medical University.

Quantitative real-time PCR ( $q R T$-PCR). According to the manufacturer's protocol, total RNA was extracted using TRIzol reagent (Invitrogen, Carlsbad, CA, USA), and first strand cDNA was synthesized using miScript Reverse Transcription kit (Qiagen). miR-205 expression was quantified by qRT-PCR using TaqMan microRNA assays (Applied Biosystems, Carlsbad, CA, USA) and U6 was used for normalization. Bcl-2 expression was quantified by qRT-PCR using SYBR-Green assays (Applied Biosystems) and $\beta$-actin was used for normalization. Real-time PCR was performed on the ABI 7500 Sequence Detection System (Applied Biosystems), and relative expression was calculated using the $2^{-\Delta \Delta \mathrm{Ct}}$ method. All experiments were performed in triplicate independently. The sequences of primers are depicted in Table II.

miRNA mimics and transfection. miR-205 mimics, the negative control pre-miR (miR-NC) and the miR-205 inhibitors provided by RiboBio (Guangzhou, China) were transfected into SW-13 cells using Lipofectamine 2000 (Invitrogen) in accordance with the manufacturer's manual.

Cell proliferation assay. SW-13 cells transiently transfected with miR-205, miR-NC and miR-205 inhibitors were cultured in 96 -well plates $\left(4 \times 10^{3}\right.$ cells/well) for $24 \mathrm{~h}$. Cell proliferation was measured via MTT assay (KeyGen, China) and further verified using a 5-ethynyl-2'-deoxyuridine (EdU) assay (RiboBio) following the manufacturer's instructions. SW-13 cells incorporating EdU were observed under fluorescent microscopy. Cell proliferation was measured using the following formula: SW-13 cell proliferation $=$ number of EdU-positive cells/all cells x 100.

Cell apoptosis assay. Apoptosis of transfected SW-13 cells was measured using the Annexin V/Propidium Iodide (PI) Detection kit (KeyGen) following the manufacturer's
Table II. Primers used in the present study.

\begin{tabular}{ll}
\hline Primers & \multicolumn{2}{c}{ Sequence } \\
\hline miR-205 & F 5'-ACACTCCAGCTGGGTAGGTAGTTTCAT \\
& \multicolumn{1}{c}{ GTTGTT-3' } \\
miR-205 & R 5'-CTCAACTGGTGTCGTGGA-3' \\
U6 & F 5'-CTCGCTTCGGCAGCACA-3' \\
U6 & R 5'-AACGCTTCACGAATTTGCGT-3' \\
Bcl-2 & F 5'-ATTTTGTAGTCACCCACCTCTAAGG-3' \\
Bcl-2 & R 5'-CATCTCCCTTCACAGCAGAACTTAAC-3' \\
$\beta$-actin & F 5'-GGGAAATCGTGCGTGACATTAAGG-3' \\
$\beta$-actin & R 5'-CAGGAAGGAAGGCTGGAAGAGTC-3' \\
\hline
\end{tabular}

F, forward; R, reverse.

instructions. Data were analyzed by flow cytometry (BectonDickinson, Franklin Lakes, NJ, USA). In addition, SW-13 cell apoptosis was measured via TUNEL assay. Cells were stained with TUNEL (Sigma, St. Louis, MO, USA) to quantify apoptotic nuclei. At least five visual fields were observed under a fluorescent microscope for each sample.

Plasmid construction and stable overexpression of miR-205. The pre-hsa-miR-205 sequence was synthesized with the following primers by PCR: 5'-CCCAAGCTTCTGGGTGG CTGTTTTGAAAAC-3' (F), and 5'-CCGCTCGAGGAAGCA CGCACACTCCAGATG-3' (R), and subcloned into the pcDNA3.1(+) plasmid (Invitrogen) following the digestion of EcoRI and BamHI to generate the recombinant plasmid pcDNA3.1(+)-miR-205. SW-13 cells were cultured to reach $60-80 \%$ confluence, and were then transfected with pcDNA3.1(+)-miR-205 according to the Lipofectamine 2000 instructions into 24-well plates. Then, transfected cells were sorted by G418 (200 mg/l) and cultured. The expression of miR-205 was measured by qRT-PCR.

Tumor formation in nude mice. Stably transfected SW-13 cells $\left(1 \times 10^{8}\right)$ were subcutaneously injected into the flank of each nude mouse ( 3 groups of 6 mice). All animal experiments were performed following the NIH Guide for the Care and Use of Laboratory Animals. Tumor volume (V) was calculated using the formula: ( $\left.\mathrm{L} \times \mathrm{W}^{2}\right) \times 0.5$ (L, length; W, width) with a Vernier caliper.

miRNA target prediction. The predicted target genes and their conserved sites of the seed region binding with each miRNA were investigated using TargetScan (http://www.targetscan. org) and miRSVR (http://www.microrna.org).

Plasmid construction and luciferase reporter assay. mRNA of wild-type Bcl-2-3'UTR (3,906-3,928 nt; GenBank accession no.NM_000633) containing binding sequence complementary to miR-205 was digested by $X b a \mathrm{I}$ and FseI and cloned downstream of the pGL3-REPORT luciferase vector (Promega, Madison, WI, USA). Based on the wild-type plasmid, site-specific mutagenesis generated mutated Bcl-2-3'UTR 
complementary to miR-205. For the luciferase reporter assay, SW-13 cells were co-transfected with wild-type or mutated Bcl-2-3'UTR and miR-205 transiently, and the luciferase was measured with a Dual-Luciferase Assay System (Promega) $48 \mathrm{~h}$ later. Each reporter plasmid was transfected at least three times.

Western blotting. After being stably transfected with plasmid or miR-205, proteins extracted from SW-13 cells were subjected to SDS-PAGE and transferred to PVDF membranes. The membrane was incubated with specific primary antibodies against Bcl-2, Bax (Santa Cruz Biotechnology, Santa Cruz, CA, USA), caspase-9 and -3 (Cell Signaling Technology, Danvers, MA, USA) at $4^{\circ} \mathrm{C}$ overnight. After washing with phosphate-buffered saline (PBS), the blotted membrane was incubated with HRP-conjugated anti-mouse or anti-rabbit IgG $(1: 2,000)$ (RiboBio) at room temperature for $2 \mathrm{~h}$. $\beta$-actin was used as an internal control. The signal was detected as previously described (15).

Immunohistochemical (IHC) assay. IHC staining of xenograft tumor slices was performed according to published methods. Then, 3- $\mu \mathrm{m}$-thick slices were incubated with diluted primary antibody against Bcl-2 (Santa Cruz Biotechnology) at $4^{\circ} \mathrm{C}$ overnight. After removing the residual primary antibody, HRP-polymer-conjugated secondary antibody was applied at $37^{\circ} \mathrm{C}$ for $1 \mathrm{~h}$. Next, slices were counterstained with hematoxylin. Three fields were selected for quantification of percentages of positive tumors and the staining intensity.

Statistical analysis. Data are presented as means \pm SEM. Differences among groups were detected with the Student's t-test and ANOVA. P-values $<0.05$ were considered to indicate a statistically significant result.

\section{Results}

Expression of miR-205 decreases in ACC tissues. To understand the role of miR-205 in ACC, expression of miR-205 was measured in both ACC $(n=11)$ and ACA tissues $(n=21)$ using qRT-PCR. We noted less expression of miR-205 in ACC tissues compared to ACAs ( $\mathrm{P}=0.008)$ (Fig. 1). Thus, miR-205 has a tumor-suppressor role in ACC.

miR-205 reduces proliferation and induces apoptosis of SW-13 cells. SW-13 cells were transfected with miR-205 mimics, miR-NC and miR-205 inhibitors and miR-205 expression was measured by qRT-PCR (Fig. 2A). In an MTT assay, significantly decreased proliferation was observed over time in cells expressing miR-205 compared with cells expressing miR-NC. miR-205 inhibitors promoted cell proliferation as well ( $\mathrm{P}<0.05$, Fig. 2B). In addition, an EdU assay was used to measure effectiveness of miR-205 on SW-13 cell proliferation. EdU, acting as a thymidine analogue replaces thymine $(\mathrm{T})$ in replicating DNA (16). We observed that SW-13 cells incorporating EdU in the miR-205 group were significantly decreased when compared to the miR-NC group. In contrast, miR-205 inhibitors increased SW-13 cell DNA replication $(\mathrm{P}<0.05$, Fig. 2C). Thus, SW-13 DNA replication was inversely related to miR-205 expression.

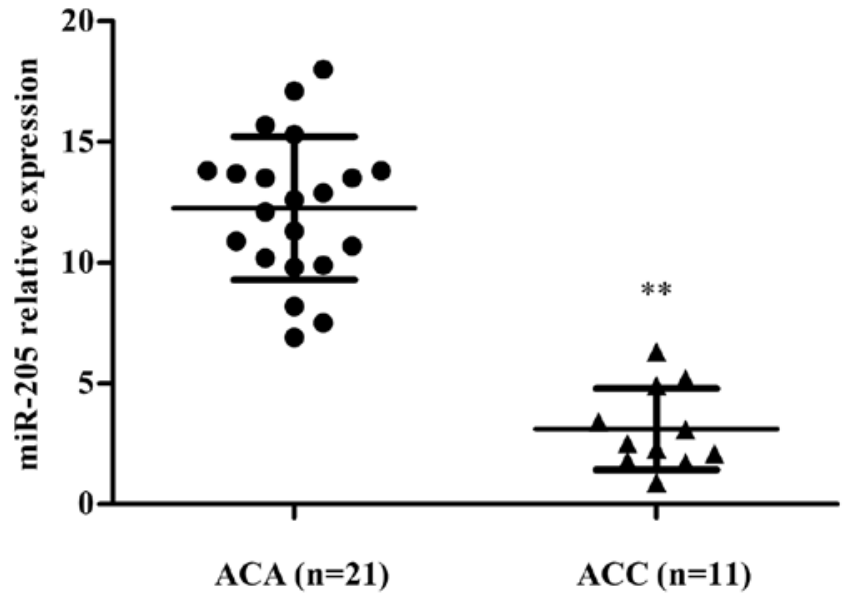

Figure 1. miR-205 expression in ACC and ACA tissues $\left({ }^{* *} \mathrm{P}<0.01\right)$. ACC, adrenocortical carcinoma; ACA, adrenocortical adenoma.

To identify the cause of reduced cell proliferation, we measured apoptosis using Annexin V/PI and TUNEL assays. The proportion of apoptotic SW-13 cells transfected with miR-205 was greater than the miR-NC group. miR-205 inhibitors decreased apoptotic proportions according to the Annexin V/PI assays ( $<<0.05$, Fig. 2D). Similarly, SW-13 apoptosis was significantly increased due to miR-205 and was reduced due to miR-205 inhibitor according to TUNEL assay data (Fig. 2E, P<0.05). Thus, inhibition of SW-13 cell proliferation by miR-205 was associated with increased apoptosis.

miR-205 inhibits tumor growth in vivo. To investigate the effect of miR-205 on tumor formation, we established SW-13 cells stably overexpressing miR-205 by the eukaryotic expression vector pcDAN3.1(+). Then, miR-205 expression was measured by qRT-PCR (Fig. 3A). Tumors in the subcutaneous nude mouse model were palpable in $\sim 7$ days in the miR-NC and untreated groups, whereas tumors in the miR-205 group were palpable $\sim 2$ weeks after inoculation. All mice developed tumors at the end of the experiment (Fig. 3B). The mean tumor volume of the miR-205 group was reduced by $>80 \%$ when compared to the miR-NC group ( $\mathrm{P}<0.05$, Fig. $3 \mathrm{C})$. miR-NC and untreated animals were not different with respect to tumor volume. Thus, elevated miR-205 in SW-13 cells reduced their ability to form tumors and miR-205 suppresses proliferation of SW-13 cells in the animal model.

miR-205 induces $S W-13$ cell apoptosis by targeting the 3'UTR of Bcl-2. To learn how miR-205 induces SW-13 cell apoptosis, bioinformatics databases were used to predict several target genes of miR-205, including Lin28, Bak1, Cbx7 and Bcl-2. $\mathrm{Bcl}-2$, an anti-apoptotic gene that is important to numerous tumors. We hypothesized that miR-205 promotes apoptosis and inhibits proliferation of SW-13 cells by targeting the Bcl-2 gene.

First, the 3'UTR of Bcl-2 containing either a wild-type or mutant binding sequence complementary to miR-205 was cloned into a luciferase reporter plasmid (Fig. 4A). miR-205 reduced luciferase activity of wild-type Bcl-2 ( $80 \%)$ in SW-13 cells $(\mathrm{P}<0.05$, Fig. $4 \mathrm{~B})$, yet it failed to repress the mutated one. To estimate whether miR-205 downregulated 

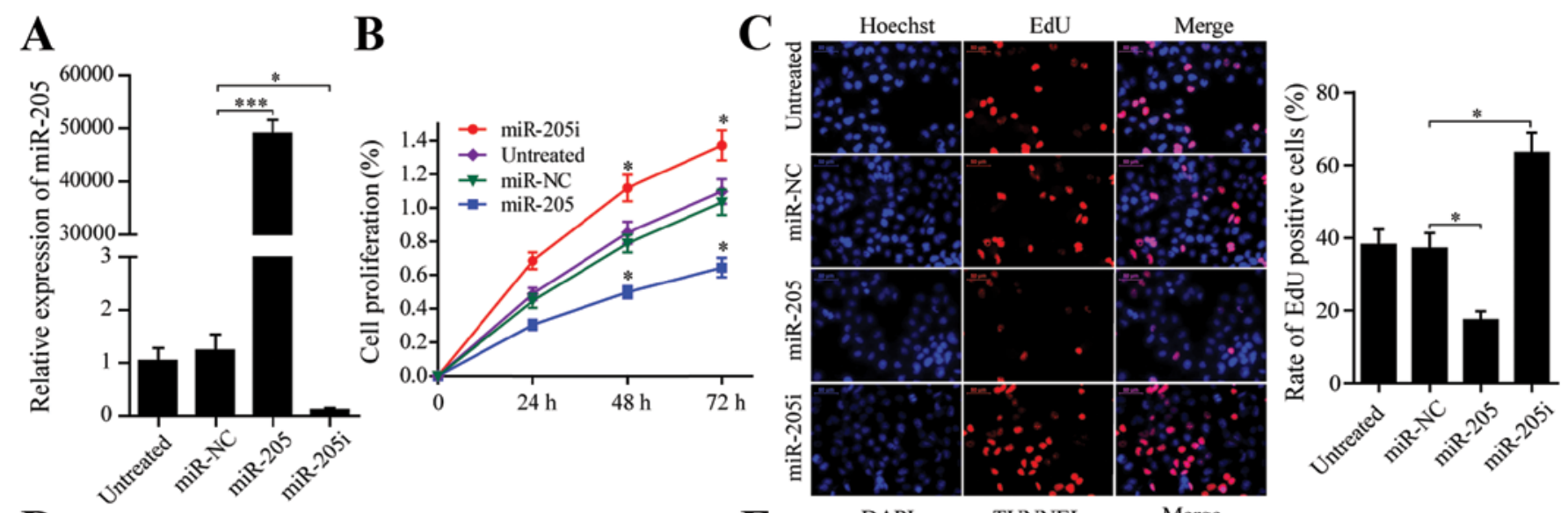

D

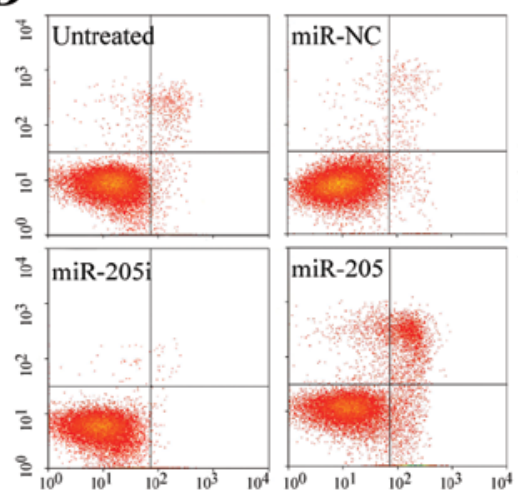

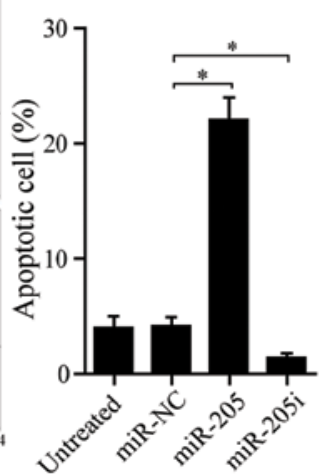

$\mathbf{E}$
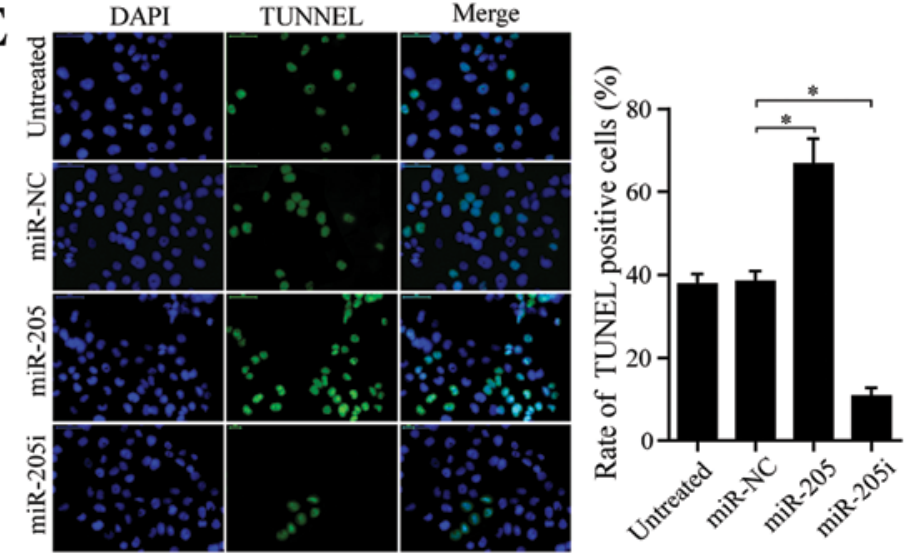

Figure 2. (A) Relative expression of miR-205 in transiently transfected SW-13 cells. (B and C) Cell proliferation measured by MTT and EdU assays. (D and E) Cell apoptosis measured by Annexin V/PI and TUNEL assays. Data are based on experiments performed independently in triplicate. ( $\mathrm{P}<0.05$, ${ }^{* * * *} \mathrm{P}<0.001$; miR-NC, negative control pre-miR; miR-205i, miR-205 inhibitors).
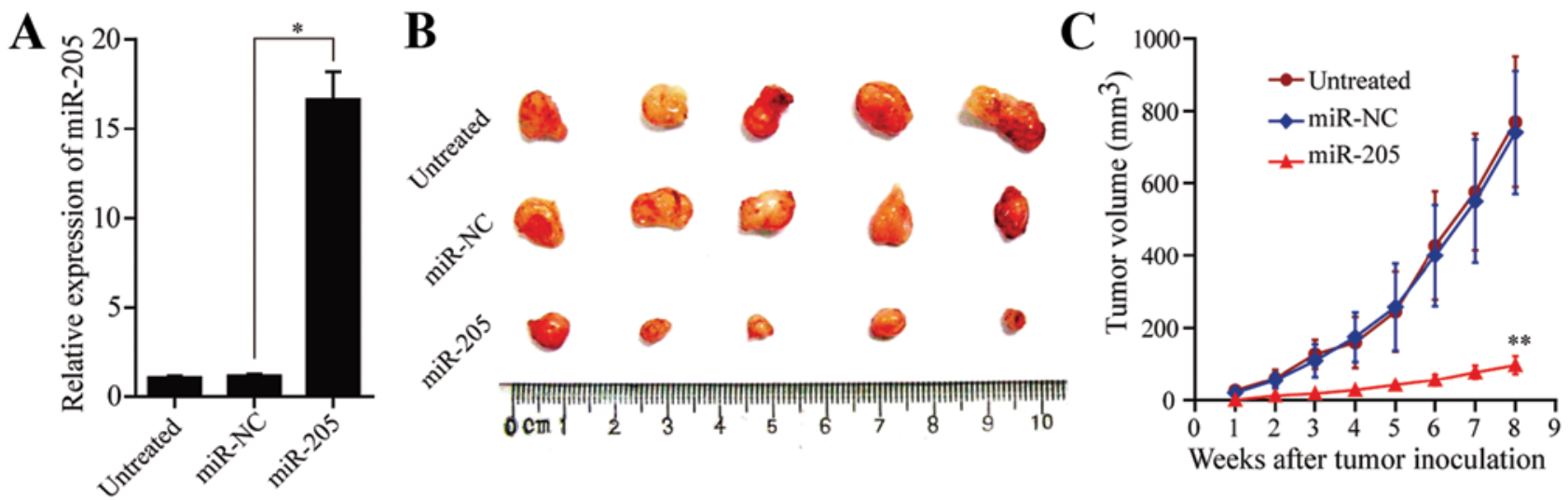

Figure 3. miR-205 inhibits SW-13 cell tumor growth. (A) Relative expression of miR-205 in stably transfected SW-13 cells. (B) Images of tumor xenograft in nude mice. (C) Effects of miR-205 on the growth of xenograft tumors, tumor sizes are shown as means \pm SEM. $\left({ }^{* *} \mathrm{P}<0.01\right)$.

Bcl-2 expression functionally, qRT-PCR analysis was used to confirm that stably overexpressing miR-205 reduced mRNA expression of Bcl-2 compared to the miR-NC group $(\mathrm{P}<0.05$, Fig. 4B). Western blotting was used to quantify expression of Bcl-2 protein due to miR-205 overexpression (Fig. 4C). IHC staining confirmed that $\mathrm{Bcl}-2$ expression was negatively correlated with that of the miR-205 in xenograft tumor tissues (Fig. 4D). Therefore, miR-205 targets Bcl-2 through 3'UTR and regulates mRNA and protein expression.
miR-205 inhibits $B c l-2$ expression via the intrinsic apoptotic pathway. Bcl-2 is reported to be a vital anti-apoptotic gene. Activation of Bcl-2 inhibits apoptosis by cleaving Bax, releasing cytochrome $c$, caspase- 9 and -3 which are involved in the intrinsic apoptotic pathway (17). To determine whether the intrinsic apoptotic pathway is also activated through miR-205-mediated suppression of Bcl-2 in SW-13 cells, we measured Bax, caspase- 9 and -3 expression via western blotting and noted that these genes were upregulated at the protein 

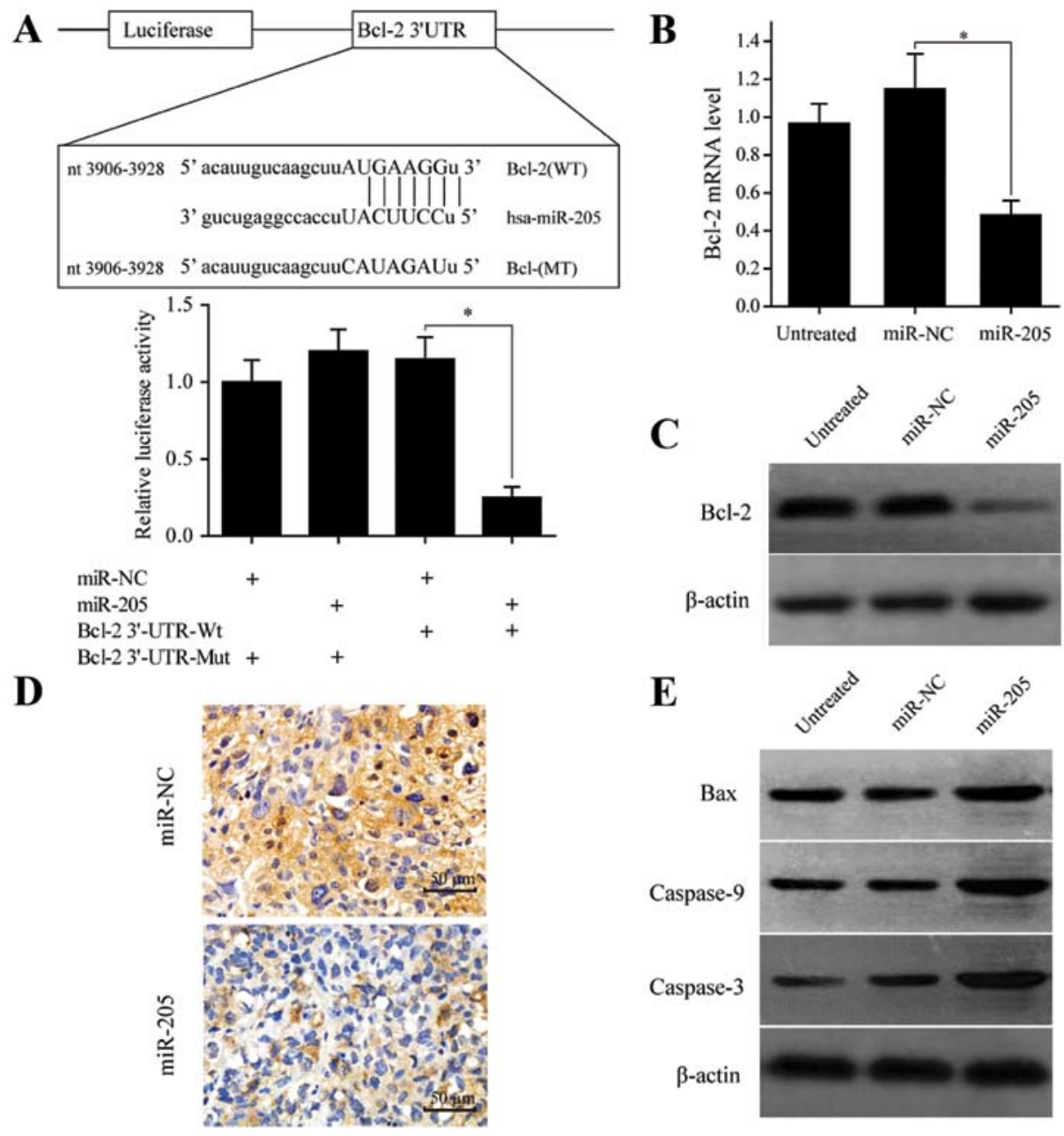

Figure 4. miR-205 induces SW-13 cell apoptosis via targeting the Bcl-2 gene. (A) The predicted miR-205 sequences contain the binding sites complementary to Bcl-2 3'UTR, including wild-type and mutant. miR-205 significantly repressed luciferase activity of wild-type Bcl-2. (B and C) Expression of Bcl-2 was verified by qRT-PCR and western blotting following stable overexpression of miR-205 in SW-13 cells. (D) Bcl-2 expression was confirmed by IHC in xenograft tumor tissues. Original magnification, x400. (E) Western blotting revealed upregulation of Bax, caspase-9 and -3 at the protein level in SW-13 cells stably overexpressing miR-205 ("P<0.05).

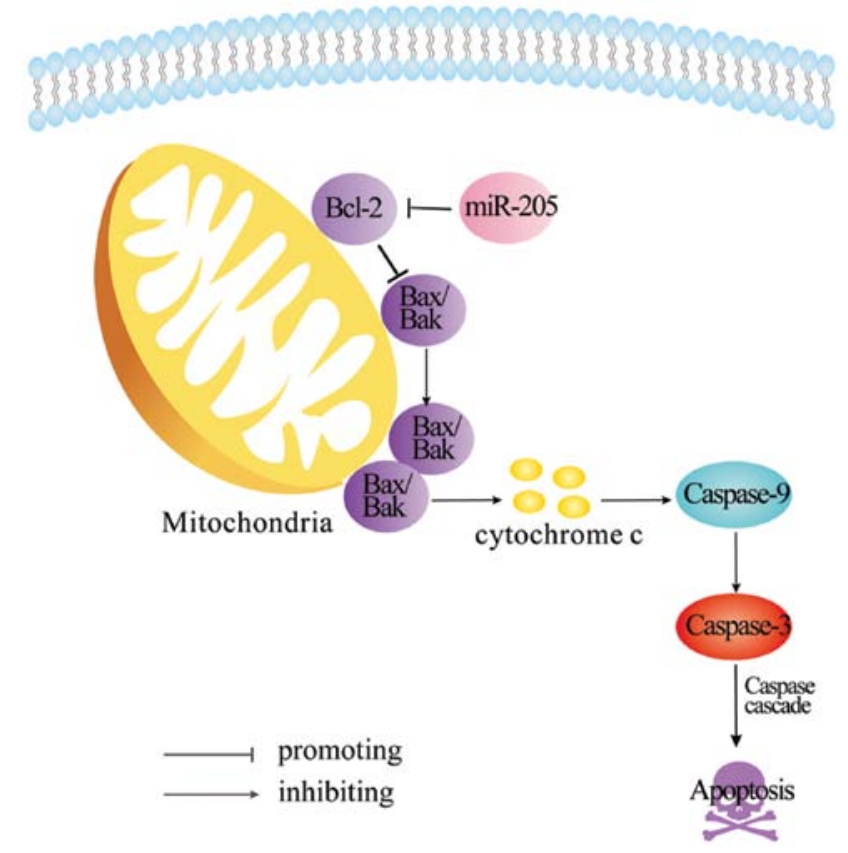

Figure 5. Suppression of Bcl-2 expression resulted in cleaving Bax, releasing cytochrome $c$, caspase- 9 and -3 involved in the intrinsic apoptosis pathway due to miR-205, which induced SW-13 cell apoptosis. 
level in miR-205-overexpressing SW-13 cells (Fig. 4E). Therefore, the Bcl-2-mediated intrinsic apoptotic pathway plays an important role in inducing SW-13 cell apoptosis due to miR-205.

\section{Discussion}

Research shows that miRNAs are critical regulators in various biological pathways and pathologic processes, including initiation and progression of cancer (9). miRNAs in tumors are thought also to modulate oncogenic or tumor suppressive pathways (18). Recently, the expression of miRNAs was confirmed in adrenocortical tumors and the goal was to identify miRNAs to differentiate adenomas from carcinomas. For instance, miR-483 was upregulated and miR-195 was downregulated in ACC compared with ACA $(4,19)$, indicating a potential value of miRNAs in diagnosing ACC. Despite these advances, little is known about the composition and characteristic of miRNAs in ACC, and few targets of miRNAs in ACC have been identified.

We reported that miR-205 is downregulated in ACC compared to ACA, and overexpression of miR-205 not only induced apoptosis and impaired proliferation of SW-13 cells, but also repressed tumor growth in vivo. Thus, miR-205 functions as an anti-oncogene in ACC. The role of miRNAs in tumors depends on the tumor origin and tissue specificity. The known functions of miR-205 include inhibition of epithelial to mesenchymal transition (EMT) via significant suppression of E-cadherin, which is related to metastasis $(20,21)$. In contrast, miR-205 regulated target genes by direct cleavage of mRNA or inhibition of protein synthesis through complementarity with 3 'UTR. At this time, few genes have been identified as targets of miR-205, including anti-oncogenes PTEN (22) and SHIP2 (23), the oncogenes HER3 (24) and PKC $\varepsilon$ (25), and the angiogenic factor VEGFA (26), and finally the pro-metastatic genes Zeb1 and Zeb2 (27). In the present study, we propose that the $\mathrm{Bcl}-2$ gene is a target of miR-205 through bioinformatics prediction software, and these data were verified by luciferase assay. mRNA and protein expression of Bcl-2 were negatively related to miR-205 in SW-13 cells and xenograft tumor tissues, suggesting that miR-205 inhibits tumor progression through targeting the 3'UTR of Bcl-2 in ACC. In addition, miR-205 was a tumor-suppressing gene by targeting $\mathrm{Bcl}-2$ which has been documented in prostate cancer (28).

In the embryo stage, the fetal cortex accounts for $85 \%$ of the adrenal cortex but disappears quickly due to apoptosis after birth $(29,31)$. Thus, it was speculated that similarities may exist between normal cortex and ACC which originated from defective apoptosis of the fetal cortex (31-33). Consequently, the research on apoptosis-related genes could be of great significance not only to provide new views to the biology of ACC, yet also to search potential prognostic and therapeutic markers. $\mathrm{Bcl}-2$ predominantly localizes to the mitochondria which is the central coordinator of the apoptotic pathway (34). Bcl-2 is reported to vary from ACC to ACA at the mRNA expression level (35), yet the mechanism of Bcl-2 action is unclear. In the present study, we found that miR-205 is an upstream regulator inhibiting Bcl-2 expression. Also, the intrinsic apoptotic pathway was activated and this promoted caspasedependent apoptosis in SW-13 cells (Fig. 5). Notably, other
miRNAs target Bcl-2 to induce cancer-cell apoptosis, among them, miR-15/miR-16 and miR-148a negatively regulated $\mathrm{Bcl}-2$ expression to induce leukemic and colorectal cancer cell apoptosis, respectively $(36,37)$. In addition, miR-181b modulates multidrug resistance by targeting $\mathrm{Bcl}-2$ in lung cancer cell lines (38). Thus, miR-205 with other miRNAs, targets $\mathrm{Bcl}-2$ to create a network to regulate tumor cell death.

In conclusion, miRNA-205 serves as a tumor-suppressor in ACC by targeting anti-apoptotic Bcl-2, which induces SW-13 cell apoptosis via the intrinsic apoptotic pathway. Our results may provide a foundation for considering miR-205 as a biomarker to aid in the diagnosis and treatment of ACC. Extensive studies are required to confirm our findings and to validate the diagnostic accuracy of these miRNAs.

\section{Acknowledgements}

The present study was supported by the China National Natural Science Foundation (nos. 81172421 and 81372744), and the Guangdong Province Natural Science Foundation of China (no. S2012010010009).

\section{References}

1. Lehmann T and Wrzesinski T: The molecular basis of adrenocortical cancer. Cancer Genet 205: 131-137, 2012.

2. Bilimoria KY, Shen WT, Elaraj D, Bentrem DJ, Winchester DJ, Kebebew E and Sturgeon C: Adrenocortical carcinoma in the United States: Treatment utilization and prognostic factors. Cancer 113: 3130-3136, 2008.

3. Kutikov A, Mallin K, Canter D, Wong YN and Uzzo RG: Effects of increased cross-sectional imaging on the diagnosis and prognosis of adrenocortical carcinoma: Analysis of the National Cancer Database. J Urol 186: 805-810, 2011.

4. Patterson EE, Holloway AK, Weng J, Fojo T and Kebebew E: MicroRNA profiling of adrenocortical tumors reveals miR-483 as a marker of malignancy. Cancer 117: 1630-1639, 2011.

5. Chiodini I: Clinical review: Diagnosis and treatment of subclinical hypercortisolism. J Clin Endocrinol Metab 96: 1223-1236, 2011.

6. Kuruba R and Gallagher SF: Current management of adrenal tumors. Curr Opin Oncol 20: 34-46, 2008.

7. Maas S: Gene regulation through RNA editing. Discov Med 10: 379-386, 2010.

8. Garzon R, Marcucci G and Croce CM: Targeting microRNAs in cancer: Rationale, strategies and challenges. Nat Rev Drug Discov 9: 775-789, 2010.

9. Etheridge A, Lee I, Hood L, Galas D and Wang K: Extracellular microRNA: A new source of biomarkers. Mutat Res 717: 85-90, 2011.

10. Iorio MV and Croce CM: MicroRNAs in cancer: Small molecules with a huge impact. J Clin Oncol 27: 5848-5856, 2009.

11. Ferracin M, Veronese A and Negrini M: Micromarkers: miRNAs in cancer diagnosis and prognosis. Expert Rev Mol Diagn 10: 297-308, 2010.

12. Gilad S, Meiri E, Yogev Y, Benjamin S, Lebanony D, Yerushalmi N, Benjamin H, Kushnir M, Cholakh H, Melamed N, et al: Serum microRNAs are promising novel biomarkers. PLoS One 3: e3148, 2008.

13. Kang MH and Reynolds CP: Bcl-2 inhibitors: Targeting mitochondrial apoptotic pathways in cancer therapy. Clin Cancer Res 15: 1126-1132, 2009.

14. Aubert S, Wacrenier A, Leroy X, Devos P, Carnaille B, Proye C, Wemeau JL, Lecomte-Houcke M and Leteurtre E: Weiss system revisited: A clinicopathologic and immunohistochemical study of 49 adrenocortical tumors. Am J Surg Pathol 26: 1612-1619, 2002.

15. Jiang B, Li Z, Zhang W, Wang H, Zhi X, Feng J, Chen Z, Zhu Y, Yang L, Xu H, et al: miR-874 inhibits cell proliferation, migration and invasion through targeting aquaporin-3 in gastric cancer. J Gastroenterol 49: 1011-1025, 2014. 
16. Chehrehasa F, Meedeniya AC, Dwyer P, Abrahamsen G and Mackay-Sim A: EdU, a new thymidine analogue for labelling proliferating cells in the nervous system. J Neurosci Methods 177: 122-130, 2009

17. Skommer J, Brittain T and Raychaudhuri S: Bcl-2 inhibits apoptosis by increasing the time-to-death and intrinsic cellto-cell variations in the mitochondrial pathway of cell death. Apoptosis 15: 1223-1233, 2010.

18. Suzuki H, Maruyama R, Yamamoto E and Kai M: DNA methylation and microRNA dysregulation in cancer. Mol Oncol 6 : 567-578, 2012.

19. Soon PS, Tacon LJ, Gill AJ, Bambach CP, Sywak MS, Campbell PR, Yeh MW, Wong SG, Clifton-Bligh RJ, Robinson BG, et al: miR-195 and miR-483-5p identified as predictors of poor prognosis in adrenocortical cancer. Clin Cancer Res 15: 7684-7692, 2009.

20. Gregory PA, Bert AG, Paterson EL, Barry SC, Tsykin A, Farshid G, Vadas MA, Khew-Goodall Y and Goodall GJ: The miR-200 family and miR-205 regulate epithelial to mesenchymal transition by targeting ZEB1 and SIP1. Nat Cell Biol 10: 593-601, 2008.

21. Fassina A, Cappellesso R, Guzzardo V, Dalla Via L, Piccolo S, Ventura L and Fassan M: Epithelial-mesenchymal transition in malignant mesothelioma. Mod Pathol 25: 86-99, 2012.

22. Greene SB, Herschkowitz JI and Rosen JM: The ups and downs of miR-205: Identifying the roles of miR-205 in mammary gland development and breast cancer. RNA Biol 7: 300-304, 2010.

23. Yu J, Ryan DG, Getsios S, Oliveira-Fernandes M, Fatima A and Lavker RM: MicroRNA-184 antagonizes microRNA-205 to maintain SHIP2 levels in epithelia. Proc Natl Acad Sci USA 105: 19300-19305, 2008

24. Iorio MV, Casalini P, Piovan C, Di Leva G, Merlo A, Triulzi T, Ménard S, Croce CM and Tagliabue E: microRNA-205 regulates HER3 in human breast cancer. Cancer Res 69: 2195-2200, 2009.

25. Gandellini P, Folini M, Longoni N, Pennati M, Binda M, Colecchia M, Salvioni R, Supino R, Moretti R, Limonta P, et al: miR-205 exerts tumor-suppressive functions in human prostate through down-regulation of protein kinase Cepsilon. Cancer Res 69: 2287-2295, 2009.

26. Wu H, Zhu S and Mo YY: Suppression of cell growth and invasion by miR-205 in breast cancer. Cell Res 19: 439-448, 2009.

27. Gregory PA, Bert AG, Paterson EL, Barry SC, Tsykin A, Farshid G, Vadas MA, Khew-Goodall Y and Goodall GJ: The miR-200 family and miR-205 regulate epithelial to mesenchymal transition by targeting ZEB1 and SIP1. Nat Cell Biol 10: 593-601, 2008 .
28. Verdoodt B, Neid M, Vogt M, Kuhn V, Liffers ST, Palisaar RJ, Noldus J, Tannapfel A and Mirmohammadsadegh A: MicroRNA-205, a novel regulator of the anti-apoptotic protein $\mathrm{Bcl} 2$, is downregulated in prostate cancer. Int $\mathbf{J}$ Oncol 43: 307-314, 2013.

29. Mesiano S and Jaffe RB: Role of growth factors in the developmental regulation of the human fetal adrenal cortex. Steroids 62 : 62-72, 1997.

30. West AN, Neale GA, Pounds S, Figueredo BC, Rodriguez Galindo C, Pianovski MA, Oliveira Filho AG, Malkin D, Lalli E, Ribeiro R, et al: Gene expression profiling of childhood adrenocortical tumors. Cancer Res 67: 600-608, 2007.

31. Spencer SJ, Mesiano S, Lee JY and Jaffe RB: Proliferation and apoptosis in the human adrenal cortex during the fetal and perinatal periods: Implications for growth and remodeling. J Clin Endocrinol Metab 84: 1110-1115, 1999.

32. Coulter CLL: Fetal adrenal development: Insight gained from adrenal tumors. Trends Endocrinol Metab 16: 235-242, 2005.

33. El Wakil A, Doghman M, Latre De Late P, Zambetti GP, Figueiredo BC and Lalli E: Genetics and genomics of childhood adrenocortical tumors. Mol Cell Endocrinol 336: 169-173, 2011

34. Plati J, Bucur O and Khosravi-Far R: Apoptotic cell signaling in cancer progression and therapy. Integr Biol Camb 3: 279-296, 2011.

35. Fonseca AL, Kugelberg J, Starker LF, Scholl U, Choi M, Hellman P, Åkerström G, Westin G, Lifton RP, Björklund P, et al: Comprehensive DNA methylation analysis of benign and malignant adrenocortical tumors. Genes Chromosomes Cancer 51: 949-960, 2012.

36. Cimmino A, Calin GA, Fabbri M, Iorio MV, Ferracin M, Shimizu M, Wojcik SE, Aqeilan RI, Zupo S, Dono M, et al: $m i R-15$ and $m i R-16$ induce apoptosis by targeting BCL2. Proc Natl Acad Sci USA 102: 13944-13949, 2005.

37. Zhang H, Li Y, Huang Q, Ren X, Hu H, Sheng H and Lai M: MiR-148a promotes apoptosis by targeting Bcl-2 in colorectal cancer. Cell Death Differ 18: 1702-1710, 2011.

38. Zhu W, Shan X, Wang T, Shu Y and Liu P: miR-181b modulates multidrug resistance by targeting BCL2 in human cancer cell lines. Int J Cancer 127: 2520-2529, 2010. 